\title{
Type 1 cardiorenal syndrome in a patient with an acute infection caused by Trypanosoma cruzi in the Brazilian Amazon region - a case report
}

\author{
Karla Cristina Petruccelli ${ }^{[1]}$, Gabriel Castro Tavares ${ }^{[1]}$, Márcio Pinheiro Lima ${ }^{[1]}$, \\ Jessica Vanina Ortiz ${ }^{[2],[3]}$, Alba Regina Brandão ${ }^{[1]}$, Katia do Nascimento Couceiro ${ }^{[2],[3],}$ \\ João Marcos Bemfica Barbosa-Ferreira ${ }^{[2],[3],[4], ~ M o ̂ n i c a ~ R e g i n a ~ H o s a n n a h ~ d a ~ S i l v a ~ e ~ S i l v a ~}{ }^{[5],}$ \\ Maria das Graças Vale Barbosa Guerra ${ }^{[2],[3]}$ and Jorge Augusto de Oliveira Guerra ${ }^{[2],[3]}$
}

[1]. Faculdade de Medicina, Universidade Federal do Amazonas, Manaus, AM, Brasil. [2]. Programa de Pós-Graduação em Medicina Tropical, Universidade do Estado do Amazonas, Manaus, AM, Brasil.

[3]. Fundação de Medicina Tropical Dr. Heitor Vieira Dourado, Manaus, AM, Brasil.

[4]. Hospital Universitário Francisca Mendes, Manaus, AM, Brasil.

[5]. Fundação de Hematologia e Hemoterapia do Amazonas, Manaus, AM, Brasil.

\begin{abstract}
Cardiorenal syndrome type 1 (CRS 1) occurs when acute heart failure leads to acute kidney injury. There are several etiologies of CRS 1, including Chagas disease. Here, we present the first case report of CRS 1 in a patient with acute Chagas disease. Electrocardiography, transthoracic echocardiography, and cardiac magnetic resonance imaging showed signs of acute myocarditis. Laboratory examination revealed severe loss of kidney function, with a creatinine clearance of $30 \mathrm{~mL} / \mathrm{min}$, which fully normalized after treatment. Due to emergence of Chagas disease in the Brazilian Amazon, it is important to report unique clinical features in order to improve patients' outcomes.
\end{abstract}

Keywords: Acute kidney failure. Chagas disease. Brazilian Amazon.

\section{INTRODUCTION}

Cardiorenal syndrome (CRS) is a pathophysiological disorder in which an acute or chronic dysfunction of one organ causes another acute or chronic dysfunction in another. It can be subdivided into five subtypes: type 1 - acute heart failure causing acute renal failure, type 2 - chronic heart failure causing renal failure, type 3 - acute renal failure causing cardiac insufficiency, type 4 - chronic renal failure causing heart failure, and type 5 , in which a systemic condition leads to cardiac and renal impairment ${ }^{1}$. Approximately $27 \%$ of patients admitted to hospital for heart failure develop acute renal injury. There are several etiologies of cardiovascular complications that can result in type 1 CRS, among them is Chagas disease (CD) ${ }^{2}$.

Chagas disease is caused by Trypanosoma cruzi, and can be transmitted by several routes, with vectorial transmission being the most traditional pathway, particularly in areas where triatomines are domiciled. Oral transmission occurs through

Corresponding author: Karla Cristina Petruccelli.

e-mail: kapeisrael@gmail.com

Received 22 April 2018

Accepted 13 July 2018 ingestion of infected vectors and reservoirs by susceptible mammals, and is considered in recent years to be responsible for outbreaks of the acute form, particularly in the Amazon region ${ }^{3,4}$.

Considered endemic in Latin America since its description by Carlos Chagas in 1909, CD has experienced a significant change in its epidemiological profile in recent decades due to the increase in immigration, resulting in its importation into previously non-endemic countries such as the United States, Canada, Switzerland, and Spain ${ }^{5}$. The Brazilian Amazon Region, long considered an area free of $\mathrm{CD}$, has recorded several outbreaks of the disease, many of them related to oral transmission due to the consumption of açaí fruit in natura $a^{6,7}$.

The acute cardiac manifestations of $T$. cruzi infection are characterized by myocarditis, pericarditis or electrical conduction disturbances, which in vector-transmitted cases resolve between 1-2 weeks after infection. Cases transmitted orally show a higher precocity of symptoms, a higher incidence of myocarditis and greater lethality when compared to cases transmitted by vectors ${ }^{8,9}$.

Here we present the first report describing the occurrence of CRS due to acute T. cruzi infection in the state of Amazonas, Brazil. 


\section{CASE REPORT}

A 43-year-old male chainsaw operator from the municipality of Atalaia do Norte, Amazonas, Brazil, presented with a threeday history of fever, chills, headache, and myalgia, and sought medical care at the Fundação de Medicina Tropical Dr. Heitor Vieira Dourado in Manaus, Amazonas (Figure 1). A thick blood smear test was done to investigate Plasmodium sp. infection but showed positivity for T. cruzi instead, and hospital admission was requested. On admission, the patient presented pain on deep palpation of the epigastrium and the liver was palpable at $4 \mathrm{~cm}$ from the rib cage but was non-tender. His heart rate was $60 \mathrm{bpm}$.

One day after admission, the patient presented oliguria and altered renal function examination, with a creatinine clearance of $30 \mathrm{~mL} / \mathrm{min}$ and creatine phosphokinase level of $1726 \mathrm{U} / \mathrm{L}$. The creatinine clearance increased to $48 \mathrm{~mL} / \mathrm{min}$ two days after the initial measurement. The results of the hepatic and renal biomarkers, as well as other biochemical parameters are presented in Table 1.

He did not present signs or symptoms of heart failure, although cardiac examination yielded signs of acute myocarditis: (1) alteration of ventricular repolarization in the anterolateral wall on the electrocardiogram (Figure 2); (2) left ventricular ejection fraction of $45 \%$, diffuse hypokinesia, mild left ventricular enlargement, and systolic dysfunction of a discrete degree on two-dimensional echocardiogram and (3) minimal pericardial effusion with a slight increase in ventricular diameters and volumes on cardiac magnetic resonance imaging.
Treatment with benznidazole (Rochagan ${ }^{\circledR}$ ) $5-7 \mathrm{mg} / \mathrm{kg}$ for 60 days was initiated following the guidelines of the $2^{\text {nd }}$ Brazilian Consensus on $\mathrm{CD}^{7}$. After the fifth day of hospitalization, and the third day of treatment, there was an improvement in symptoms, but with a persistent positivity in the thick blood smear. New examinations were performed fifteen days after admission in which the thick blood smear showed negative results. Three months later, in the outpatient follow-up, cardiac examinations were repeated and showed normal findings, the transthoracic echocardiogram showed an ejection fraction of $70 \%$, and laboratory examination confirmed the complete normalization of the glomerular filtration rate.

\section{DISCUSSION}

Although considered endemic in Latin America, CD in the Brazilian Amazon region has undergone a significant change in its epidemiological profile associated with the consumption of contaminated food, such as açaí fruit in natura ${ }^{7}$. The acute myocarditis presented by the patient described was associated with and probably caused the acute renal failure, which completely resolved after treatment. This is the first report describing the occurrence of CRS probably due to acute T. cruzi infection in the Brazilian Amazon region.

T. cruzi has a tropism mainly for cardiac cells, but may also proliferate in renal cells, though organ involvement is rare and poorly studied. Previous studies have already demonstrated the existence of structural and functional changes, such as proximal tubular epithelial lesion and decreased renal blood flow.

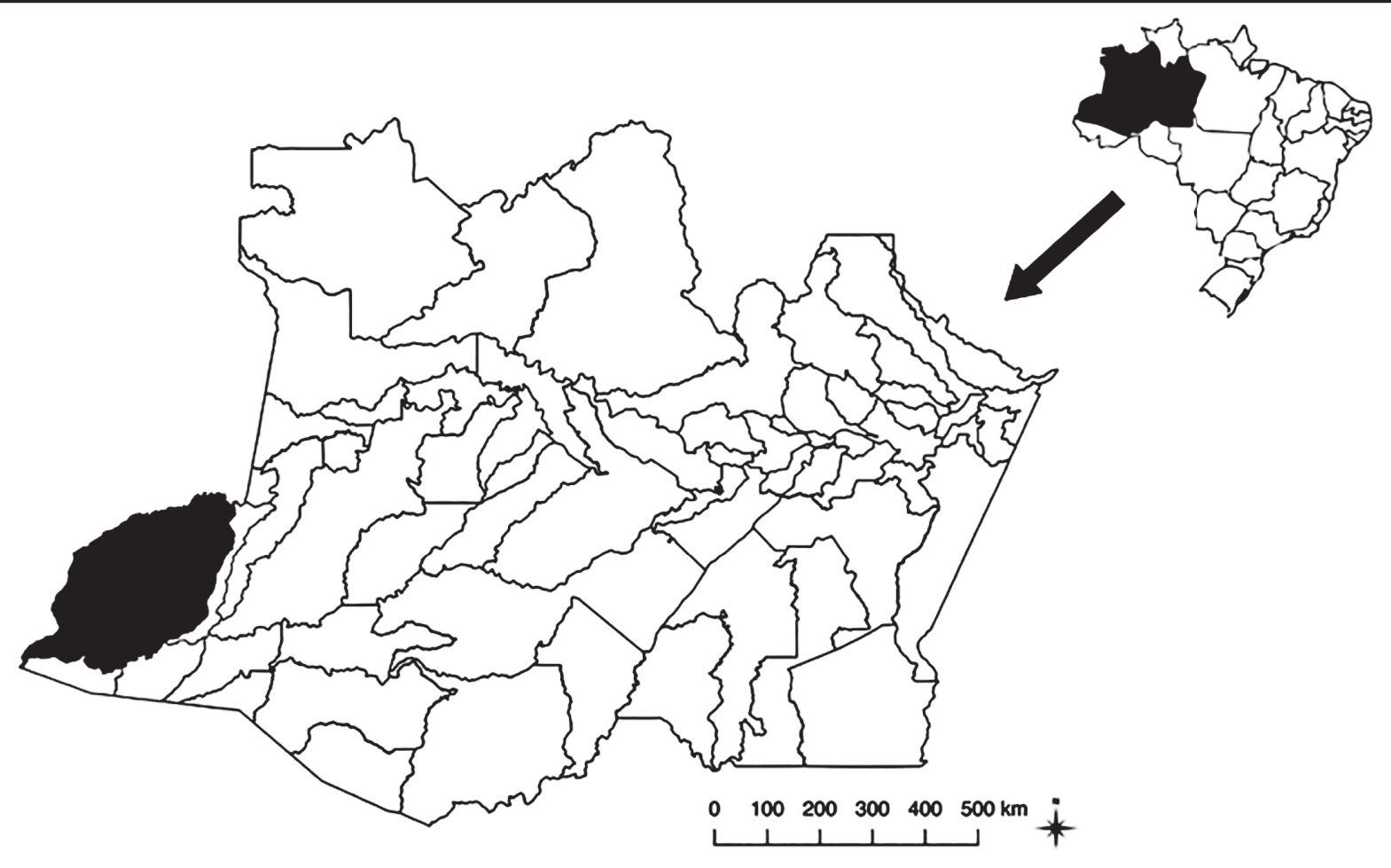

FIGURE 1: Map of the location of Atalaia do Norte, state of Amazonas, Brazil. 
TABLE 1: Admission and follow-up laboratory exams.

\begin{tabular}{|c|c|c|c|c|c|c|}
\hline Exams & $02 / 28$ & 03/02 & $03 / 06$ & $03 / 13$ & $03 / 20$ & Reference \\
\hline WBC $\left(/ \mathrm{mm}^{3}\right)$ & 2160 & 3050 & 6440 & 9420 & 7080 & $4000-10000$ \\
\hline Platelets (/mm) & 80000 & 75000 & 210000 & 638000 & 534000 & $15000-400000$ \\
\hline Urea (mg/dL) & 69 & 62 & 22 & 23 & 31 & $10-45$ \\
\hline Creatinine $(\mathrm{mg} / \mathrm{dL})$ & 1,8 & 1,7 & 0,7 & 0,8 & 0,9 & $0,6-1,2$ \\
\hline $\mathrm{LDH}(\mathrm{U} / \mathrm{L})$ & 1436 & 1503 & 1259 & 902 & - & $140-280$ \\
\hline ALT (IU/L) & 264 & 233 & 191 & 90 & 59 & $2-44$ \\
\hline Bilirubin (mg/dL) & 2,69 & - & - & 1,01 & 0,69 & $0,2-1,2$ \\
\hline Sodium (mg/dL) & 134 & - & 139 & 139 & 137 & $135-145$ \\
\hline Potassium (mmol/L) & 3,7 & 3,8 & 3,5 & 4,1 & 4,5 & $3,6-5,2$ \\
\hline Creatinine kinase $(\mathrm{U} / \mathrm{L})$ & - & 1726 & 106 & - & - & $52-336$ \\
\hline Amylase (U/L) & 40 & 0 & 25 & - & - & $40-140$ \\
\hline
\end{tabular}

RBC: red blood cells; WBC: white blood cells; LDH: lactate dehydrogenase; GGT: gamma-glutamyltransferase; AST: aspartate aminotransferase; ALT: alanine aminotransferase.

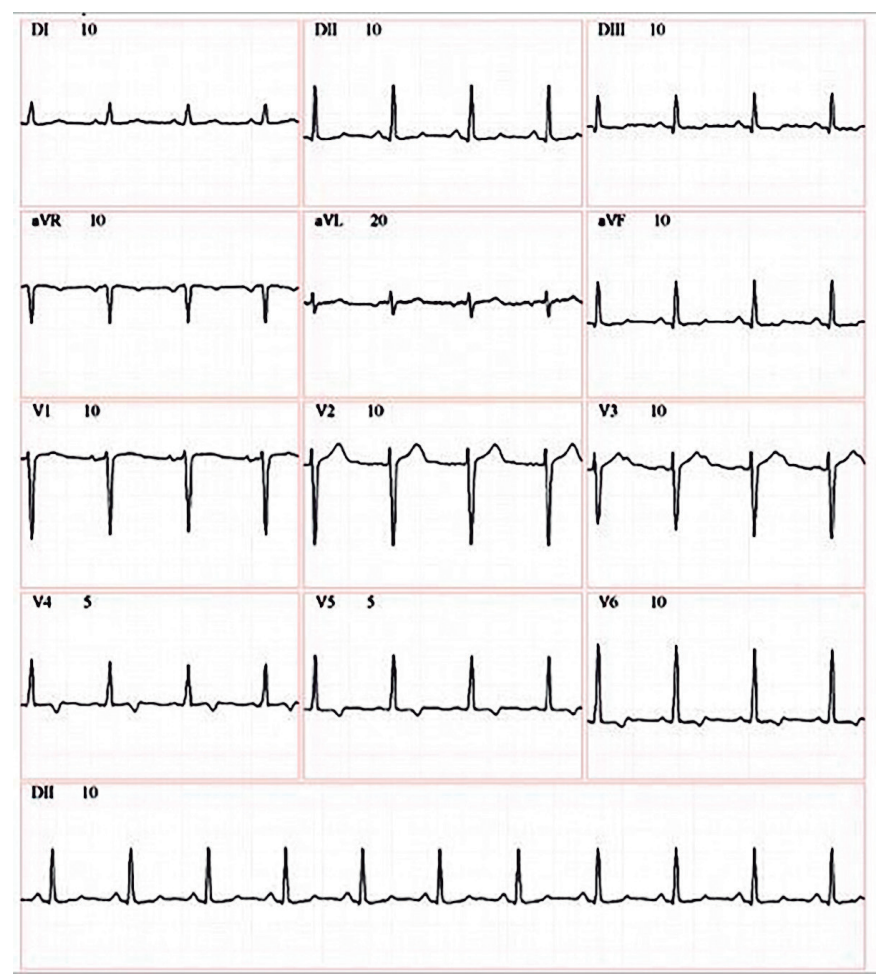

FIGURE 2: Electrocardiogram showing alteration of ventricular repolarization in the anterolateral wall. 
Significant interstitial inflammatory infiltrates and increased pro-inflammatory cytokines are observed, as well as increased renal size. Acute renal failure may occur when parasitemia is very high ${ }^{10,11}$.

The pathogenesis of cardiorenal syndrome type 1 (CRS 1) involves a series of mechanisms not yet fully clarified. Situations in which there is left ventricular dysfunction with reduction in cardiac output and subsequent reduction in renal blood flow lead to a continuous activation of the renin-angiotensin-aldosterone system (RAAS) and consequent retention of sodium and water, vasoconstriction and reduction of the glomerular filtration rate. In CRS 1 these processes are potentially reversible, with appropriate support measures in place ${ }^{2}$.

CRS management involves hemodynamic support aimed at improving cardiac function mainly through inotropic use, RAAS antagonists, vasodilators, and beta-blockers. It is also important to reduce volume overload either by diuretic therapy or renal replacement therapy ${ }^{12}$. The use of benznidazole is not formally contraindicated in renal failure, but its prescription in these cases should be evaluated individually. In the present case, the severity of the patient's cardiorenal profile played a role in the choice of benznidazole, which seemed to be quite effective.

The Brazilian Amazon is a peculiar locality in which CD presents an emerging situation and therefore, still neglected and difficult to control. For that reason, it is important to study and describe the unique clinical features associated with the disease to provide an improvement in patient management. Fortunately, this was a successfully treated case in which rapid cardiac and renal clinical improvement concomitantly occurred.

\section{Conflict of Interest}

The authors declare that there is no conflict of interest.

\section{REFERENCES}

1. House AA, Anand I, Bellomo R, Cruz D, Bobek I, Anker SD, et al. Definition and classification of cardio-renal syndromes: workgroup statements from the 7th ADQI consensus conference. Nephrol Dial Transplant. 2010; 25(5):1416-20.

2. Hadjiphillipou S, Kon SP. Cardiorenal syndrome: review of our current understanding. J Royal Soc Med. 2016;09(1):12-17.

3. Coura JR. Chagas disease: what is known and what is needed - A backgroundarticle. Mem Inst Oswaldo Cruz.2007;102(Suppl.I):113-22.

4. Dias JCP, Amato NV, Luna EJA. Mecanismos alternativos de transmissão do Trypanosoma cruzi no Brasil e sugestões para sua prevenção. Rev Soc Bras Med Trop. 2011;44(3):375-9.

5. Conners EE, Vinetz JM, Weeks JR, Brouwer KC. A global systematic review of Chagas disease prevalence among migrants. Acta Tropica. 2016;156:68-78.

6. Pinto AYN, Valente SA, Valente VC, Ferreira Jr AG, Coura JR. Fase aguda da doença de Chagas na Amazônia brasileira: Estudo de 233 casos do Pará , Amapá e Maranhão observados entre 1988 e 2005. Rev Soc Bras Med Trop. 2008;41(6):602-14.

7. Barbosa MGV, Ferreira JMBB, Arcanjo ARL, Santana RAG, Magalhães LKC, Magalhães LKC, et al. Chagas disease in the state of Amazonas: history, epidemiological evolution, risks of endemicity and future perspectives. Rev Soc Bras Med Trop. 2015;48(Suppl. I):27-33.

8. Dias JCP, Ramos Jr. AN, Gontijo ED, Luquetti A, Shikanai-Yasuda MA, Coura JR, et al. II Consenso Brasileiro em Doença de Chagas, 2015. Epidemiol Serv Saúde. 2016; 25(núm. esp.):7-86.

9. Almeida DR. Insuficiência cardíaca na doença de Chagas. Rev Soc Bras Cardiol. Rio Grande do Sul. 2004;3:1-5.

10. Oliveira G, da Silva T, Batista W, Franco M, Schor N. Acute Trypanosoma cruzi experimental infection induced renal ischemic/ reperfusion lesion in mice. Parasitology Research. 2009;106(1):111-20.

11. Silva Junior G, Antunes V, Motta M, Barros E, Daher E. Chagas diseaseassociated kidney injury - a review. NefroLat. 2017;14(1):22-26.

12. Van Bommel RJ, Mollema SA, Borleffs CJ, Bertini M, Ypenburg C, Marsan NA, et al. Impaired renal function is associated with echocardiographic nonresponse and poor prognosis after cardiac resynchronization therapy. J Am Coll Cardiol. 2011;57(5):549-55. 